\title{
Forgotten double J stents with a 'Houdini'-like vanishing act
}

\author{
Ranjit Chaudhary, ${ }^{1}$ Kulwant Singh, ${ }^{2}$ Chirag Dausage, ${ }^{2}$ Rakesh Biswas ${ }^{3}$
}

${ }^{1}$ Unit of Urology, People's College of Medical Sciences, Bhopal, Madhya Pradesh, India ${ }^{2}$ Department of General Surgery, People's College of Medical Sciences, Bhopal,

Madhya Pradesh, India ${ }^{3}$ Department of Medicine, People's College of Medical Sciences, Bhopal, Madhya Pradesh, India

Correspondence to Professor Rakesh Biswas, rakesh7biswas@gmail.com

Accepted 3 May 2014
CrossMark

To cite: Chaudhary $R$, Singh K, Dausage C, et al. BMJ Case Rep Published online: [please include Day Month Year] doi:10.1136/ bcr-2014-205220

\section{DESCRIPTION}

A 56-year-old man presented to our institute with a three-month history of bilateral flank pain along with dysuria. He had undergone bilateral ureteroscopy with double $\mathrm{J}$ stenting for lower ureteric stones 3 years previously. However, the patient did not follow-up for stent removal and mentioned passing some tubular structures in his urine 1 year after the surgery.

Routine blood investigations revealed no abnormalities. Plain skiagram kidney, ureter, bladder (figure 1) revealed $5 \mathrm{~cm}$ of the upper segment of

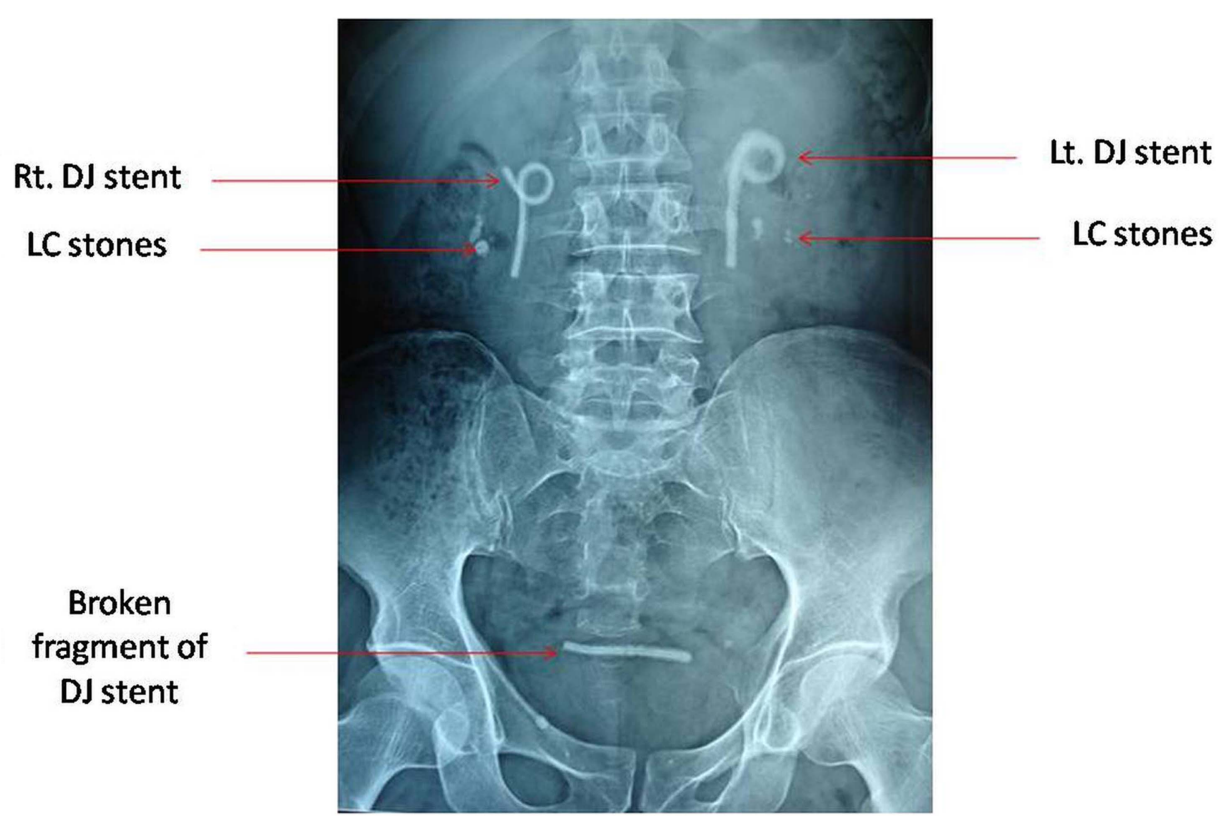

Figure 1 Plain skiagram kidney, ureter, bladder region: $5 \mathrm{~cm}$ of the upper segment of double J (DJ) stents on both sides seen with rest of the stent missing. Bilateral lower calyx stones. Broken fragment of stent seen in bladder.

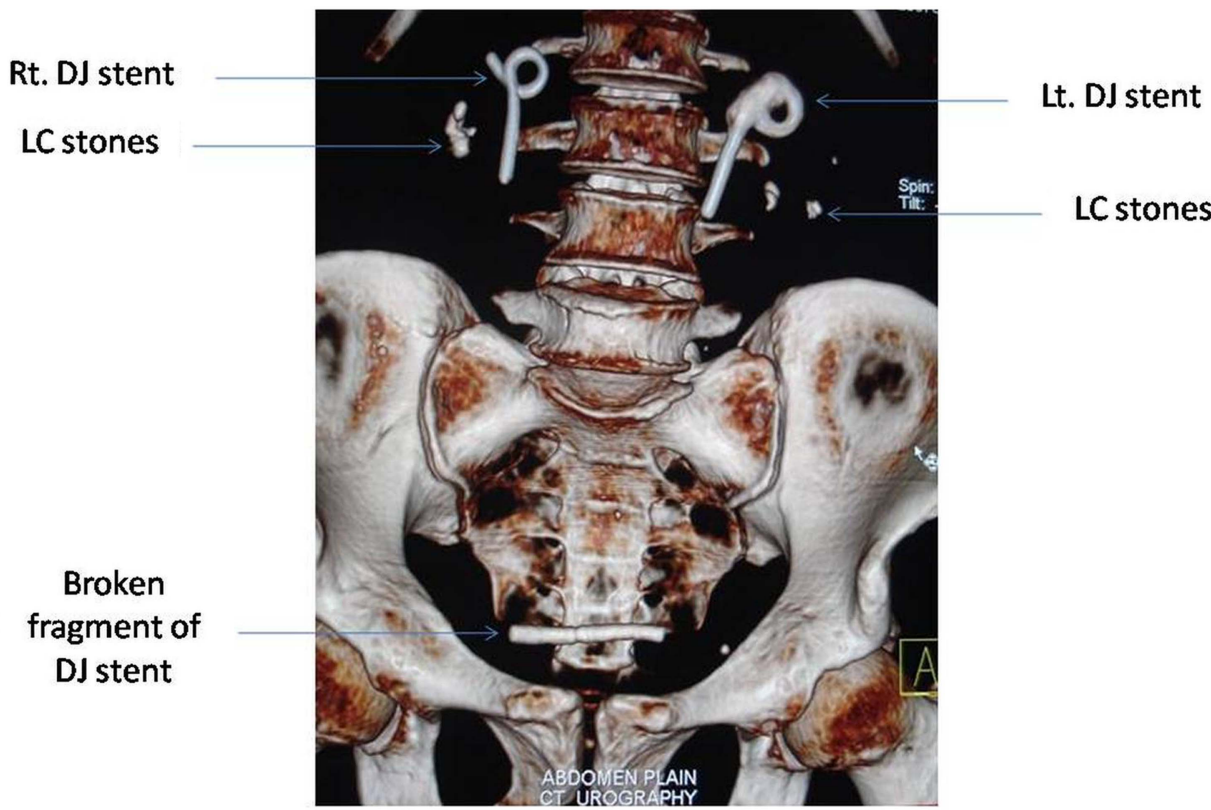

Figure 2 Non contrast computed tomography showing $5 \mathrm{~cm}$ of the upper segment of double J (DJ) stents on both sides with rest of the stent missing, bilateral lower calyx stones and broken fragment of stent in the bladder. 


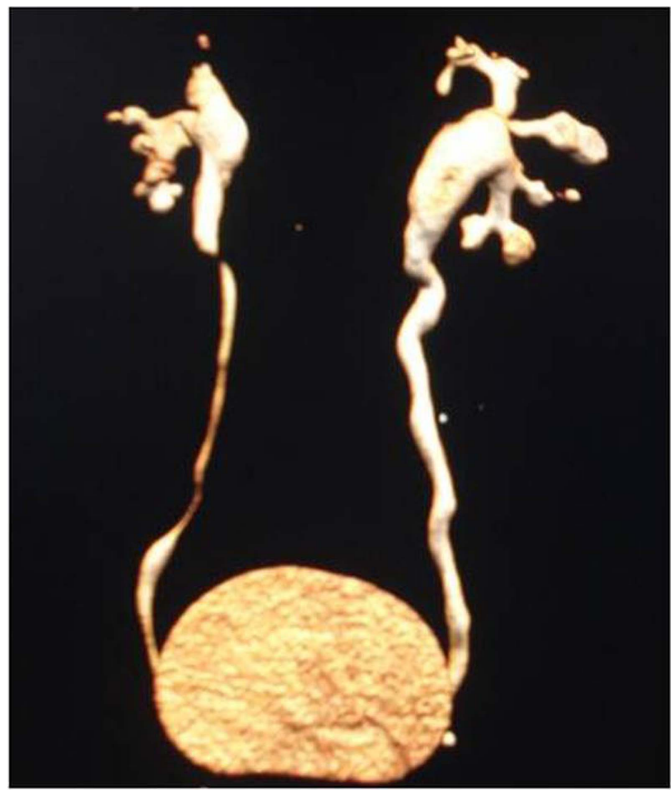

Figure 3 CT urogram.

double $\mathrm{J}$ stents on both sides with rest of the stent missing. There were few radio opacities in both kidney regions. There was another $5 \mathrm{~cm}$ linear opacity visible in the bladder region; perhaps a broken piece of stent. Ultrasonogram and CT urogram (figures 2 and 3) confirmed the above findings and demonstrated bilateral mild hydronephrosis and multiple lower calyceal stones.

The patient was subjected to endoscopic removal of stones under general anaesthesia. Cystourethroscopy was performed using a $20 \mathrm{Fr}$ sheath and $30^{\circ}$ telescope. A heavily encrusted stent fragment (figures 4 and 5) was visualised in the bladder which was removed by stent removal forceps. Owing to heavy encrustations, it was difficult to grasp the fragment. Thereafter, a right ureteroscopy was performed using a semirigid ureteroscope, $8 \times 9.8 \mathrm{Fr}$. The scope was negotiated up to the lower part of the stent, and by the help of a ballistic lithotripter, the encrustations were fragmented. However, it was not possible to remove the stent as the curl in the kidney was encrusted which could not be fragmented via the ureteroscope. Bilateral 6 Fr ureteric catheters were placed. Bilateral percutaneous nephrolithotomy (PCNL) was performed (on the right followed by the left) in the same sitting using a rigid nephroscope. Two punctures were made on both sides, in the supracostal upper calyx and subcostal lower calyx, achieving complete clearance. Stents (figures 6 and 7) were removed after partially fragmenting the encrustations. No nephrostomies or double J stents were kept on completion of

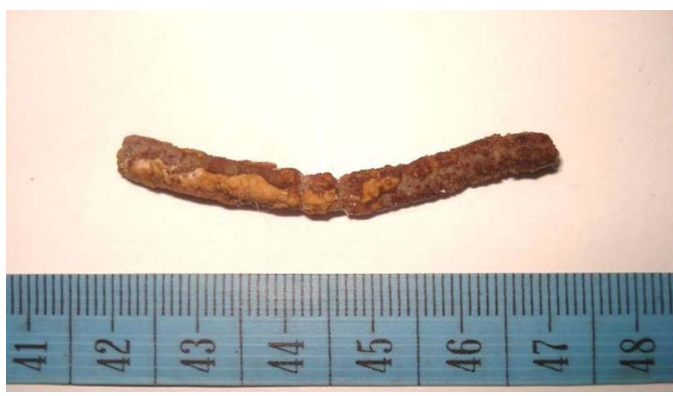

Figure 4 Extracted stent fragment from the urinary bladder.

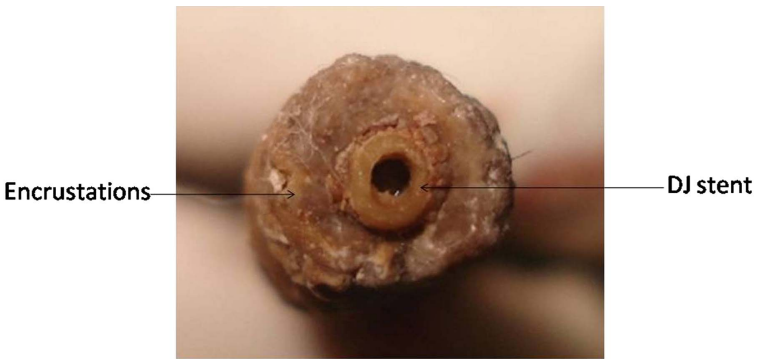

Figure 5 Severe encrustations enveloping the stent extracted from the urinary bladder.

the procedure. No blood transfusions were needed and the patient was discharged the next day.

\section{Discussion}

Double J stenting is a common urological procedure. ${ }^{1}$ However, if a stent is kept for a prolonged duration then it serves as a nidus leading to the formation of encrustations along the entire length which may result in calculus formation at the renal and vesical ends. Stents may also fracture at variable intervals. ${ }^{2}$ Both these complications were seen in the case cited above leading to a remarkable radiological appearance where barring the upper $5 \mathrm{~cm}$, the entire stent vanished from the ureter symmetrically on both sides.

Removal of such stents is almost always a challenging affair. Exerting too much force during cystoscopic removal of encrusted stents may lead to ureteric intussusceptions and may also fracture the stent. Fluoroscopic guidance should be mandatory for removal of encrusted stents to monitor uncoiling of the renal end and subsequent smooth withdrawal of the stent. Removal of stents with encrustations along the entire length usually requires ureteroscopy along with PCNL for fragmentation of encrustations.

Extracorporeal shock wave lithotripsy is indicated for localised, low-volume encrustations. However, the kidneys harbouring such stents should have reasonably good function to allow spontaneous clearance of fragments.

Flexible ureteroscopy with Holmium:YAG (Ho:YAG) laser for encrusted forgotten stents has also been reported. However, introduction of a flexible ureteroscope usually requires a ureteral access sheath (UAS). Owing to an indwelling stent, the ureter may be dilated enough to accommodate a UAS. In those cases where UAS cannot be passed, one can pass another double J

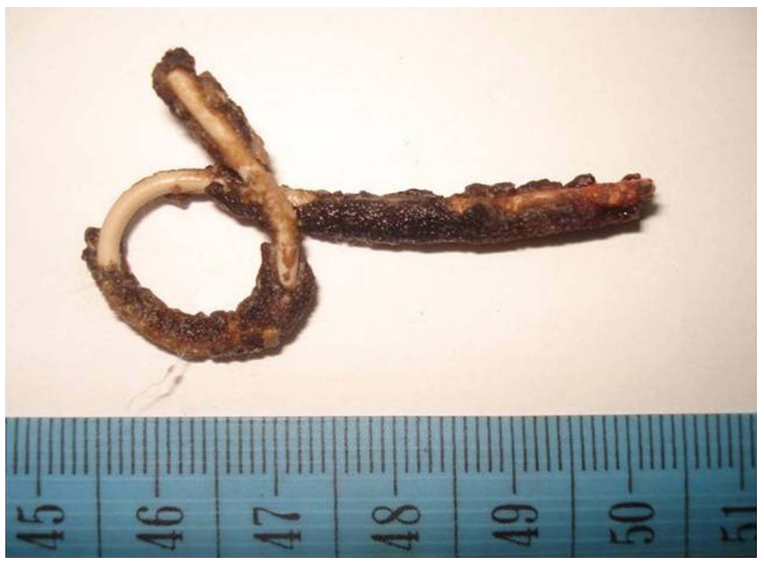

Figure 6 Right double J stent with encrustations. 


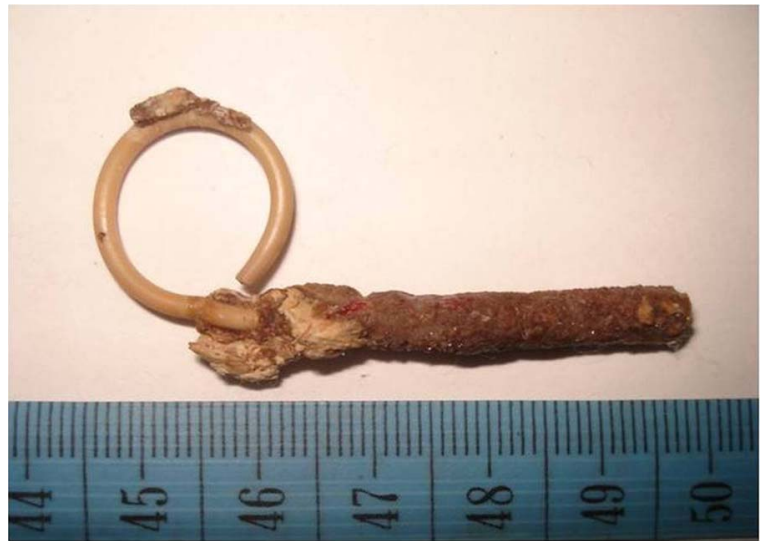

Figure 7 Left double J stent with encrustations.

stent by the side of the encrusted stent and perform flexible ureteroscopy as a staged procedure. Flexible ureteroscopy has a distinct advantage over its semirigid counterpart in the fragmentation of encrustations in the proximal part and renal end of the double J stent. Thereby encrustations along the entire length may be managed without a PCNL. However, flexible ureteroscopy should be avoided in situations where there is a suspicion of the encrusted stent being adherent to the surrounding ureteric mucosa. Moreover, while fragmenting encrustations with a laser energy source, one must be careful not to cut-off the stent.

In our personal experience, we believe double $\mathrm{J}$ stenting could be avoided in uncomplicated ureteroscopies for lower ureteric stones.

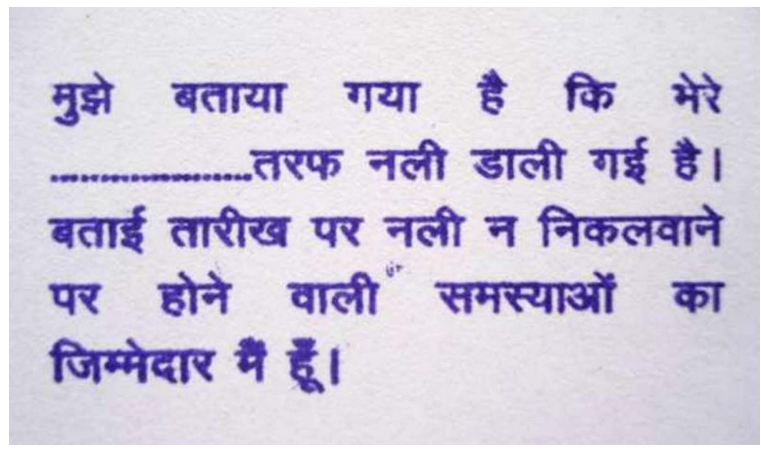

Figure 8 Printed statement notifying the indwelling stent.
In the Indian subcontinent, owing to poor levels of literacy, it is of paramount importance to adequately counsel patients and their relatives regarding the presence of stent after a procedure and the absolute need for its removal after a specified interval. If stents are to be kept for a longer duration, then the importance of thorough counselling cannot be overemphasised. We routinely put a printed statement on the discharge ticket denoting that the attendants have been notified regarding the indwelling stent and the due date for its removal (figure 8). By making the relatives undersign, it minimises chances of default and offers legal protection to the surgeon. In addition, a stent registry should be maintained by all urologists for prevention of such complications. A reminder letter, email or phone call should be made in case the patient fails to keep his or her appointment. ${ }^{3}$

\section{Learning points}

- Ideally double J stents should not be kept for more than 4-6 weeks barring exceptional circumstances. Patients and their relatives must be thoroughly counselled regarding the presence of stent and the due date for its removal.

- Removal of encrusted stents should always be performed under fluoroscopic guidance.

- Stents encrusted along the entire length usually require ureteroscopy along with percutaneous nephrolithotomy.

Contributors $\mathrm{RC}$ and $\mathrm{KS}$ had operated on the case and $\mathrm{CD}$ and RB helped in the preparation of the manuscript.

Competing interests None.

Patient consent Obtained.

Provenance and peer review Not commissioned; externally peer reviewed.

\section{REFERENCES}

1 Haleblian G, Kijvikai K, de la Rosette J, et al. Ureteral stenting and urinary stone management: a systematic review. J Urol 2008;179:424.

2 Damiano R, Oliva A, Esposito C, et al. Early and late complications of double pigtail ureteral stent. Urol Int 2002;69:136-40.

3 Lynch MF, Ghani KR, Frost I, et al. Preventing the forgotten ureteral stent: implementation of a web-based stent registry with automatic recall application. Urology 2007:70:423-6.

Copyright 2014 BMJ Publishing Group. All rights reserved. For permission to reuse any of this content visit http://group.bmj.com/group/rights-licensing/permissions.

BMJ Case Report Fellows may re-use this article for personal use and teaching without any further permission.

Become a Fellow of BMJ Case Reports today and you can:

- Submit as many cases as you like

- Enjoy fast sympathetic peer review and rapid publication of accepted articles

- Access all the published articles

- Re-use any of the published material for personal use and teaching without further permission

For information on Institutional Fellowships contact consortiasales@bmjgroup.com

Visit casereports.bmj.com for more articles like this and to become a Fellow 